\title{
3'3-Diindolylmethane inhibits migration, invasion and metastasis of hepatocellular carcinoma by suppressing FAK signaling
}

\author{
Wen-Xue Li ${ }^{1}$, Li-Ping Chen ${ }^{2}$, Min-Ying Sun ${ }^{1}$, Jun-Tao Li ${ }^{1}$, Hua-Zhang Liu ${ }^{1}$, Wei Zhu ${ }^{1}$ \\ ${ }^{1}$ Dearpartmant of Toxicology, Guangzhou Center for Disease Control and Prevention, Guangzhou, China \\ ${ }^{2}$ Faculty of Toxicology, School of Public Health, Sun Yet-sen University, Guangzhou, China \\ Correspondence to: \\ Wei Zhu, e-mail: zhuyc126@126.com \\ Keywords: hepatocellular carcinoma, focal adhesion kinase (FAK), diindolylmethane (DIM), MMP2/9, pTEN \\ Received: September 03, $2014 \quad$ Accepted: May 21, $2015 \quad$ Published: June 03, 2015
}

\section{ABSTRACT}

Late stage hepatocellular carcinoma (HCC) usually has a low survival rate because it has high potential of metastases and there is no effective cure. 3'3-Diindolylmethane (DIM) is the major product of the acid-catalyzed oligomerization of indole-3-carbinol present in cruciferous vegetables. DIM has been proved to exhibit anticancer properties. In this study, we explored the effects and molecular mechanisms of antimetastasis of DIM on HCC cells both in vitro and in vivo. We chose two HCC cell lines SMMC-7721 and MHCC-97H that have high potential of invasion. The results showed that DIM inhibited the proliferation, migration and invasion of these two cell lines in vitro. In addition, in vivo study demonstrated that DIM significantly decreased the volumes of SMMC-7721 orthotopic liver tumor and suppressed lung metastasis in nude mice. Focal Adhesion Kinase (FAK) is found over activated in HCC cells. We found that DIM decreased the level of phospho-FAK (Tyr397) both in vitro and in vivo. DIM inhibition of phospho-FAK (Tyr397) led to down-regulation of MMP2/9 and decreased potential of metastasis. DIM also repressed the migration and invasion induced by vitronectin through inactivation of FAK pathway and down-regulation of MMP2/9 in vitro. We also found that PTEN plays a role in down-regulation of FAK by DIM. These results demonstrated that DIM blocks HCC cell metastasis by suppressing tumor cell migration and invasion. The anti-metastasis effect of DIM could be explained to be its down-regulated expression and activation of MMP2/9 partly induced by up-regulation of pTEN and inhibition of phospho-FAK (Tyr397).

\section{INTRODUCTION}

Hepatocellular carcinoma(HCC) is one of the most common and aggressive human malignancies around the world, especially in developing countries [1]. Although great progress was attained in cancer treatment, most HCC patients die from cancer invasion or distant metastasis to other organs. Therefore, preventing metastasis of cancer cells is one of the effective strategies for the successful management of HCC.

The mechanism of cancer invasion and metastasis is a complicated multistep process involving multiple genetic alterations. Focal Adhesion Kinase (FAK), a $125 \mathrm{kD}$ non-receptor protein tyrosine kinase, is the key signaling nexus connecting integrins and the dynamic actin cytoskeleton to coordinate cell motility and cell invasion [2]. Interaction between integrins and extracellular matrix(ECM) lead to the activation of FAK through phosphorylation and autophosphorylation at the tyrosine 397(Tyr397). The activation of FAK is the key regulatory point for several signaling pathways. Activated FAK interacts with PI3 kinase (PI3K)-dependent Akt (PI3K/AKT) axis to interrupt apoptotic pathways and increase tumor cell migration [3-5]. Activated FAK regulates survival and metastasis signaling pathways through PI3K/AKT pathway and downstream signaling including MMPs and IAPs activation in HCC [6, 7]. Both FAK and phosphorylated FAK Tyr397 have been shown to be overexpressed in HCC samples and HCC cell lines. In addition, increased FAK and phospho-FAK (Tyr397) 
expression were correlated with tumor stage, vascular invasion and intrahepatic metastasis in HCC [2]. These data suggest that deregulation of FAK plays an important role in HCC malignant progression. Many ways for inhibition of FAK including siRNA and small molecule inhibitors has been shown to decrease cellular migration and invasion in multiple tumor types, including HCC [8-10]. Therefore, inactivation of FAK pathway could be a good way to inhibit metastasis of human HCC.

A number of studies demonstrate that diets rich in fruits and vegetables could reduce the risk of cancers through some kinds of promising anti-cancer phytochemicals in them [11]. One of the potential phytochemicals is 3'3-Diindolylmethane (DIM). DIM is the predominant active product of the acidcatalyzed oligomerization of indole-3-carbinol (I3C), a phytochemical from vegetables of the family cruciferous [12]. DIM has been reported to reduce carcinogen-induced breast and lung tumor formation in rodent models [13, 14]. The growth of bladder and breast cancer xenografts were also shown to be inhibited by DIM administration [15]. It has also been showed that DIM blocks the metastasis of many types of cancer cells both in vitro and in vivo, including breast cancer [16], prostate cancer [17, 18], lung cancer [16] and bladder cancer [19]. However, the mechanism underlying the role of DIM on HCC treatment still remains elusive. We initiated this study to investigate the anti-cancer properties of DIM and elucidate the underlying mechanisms.

In this study, we investigated the role of DIM in the anti-metastasis effect on HCC cell lines SMMC-7721 and MHCC-97H. These cells have high potential of invasion. We found that DIM dose-dependently inhibited proliferation, migration, adhesion and invasion of SMMC-7721 and MHCC-97H in vitro. Oral administration of DIM inhibited lung metastasis of SMMC-7721 xenograft in BALB/c nude mice. Furthermore, we demonstrate that DIM increased the expression of pTEN and inhibited the phosphorylation of FAK Tyr397, in succession led to the down-regulation of MMP2/9.

\section{RESULTS}

\section{DIM significantly inhibited the proliferation of HCC cells}

The inhibitory effect of DIM on HCC cells was tested on HCC cell lines including SMMC-7721, MHCC-97H, QGY-7701, Bel-7402 and HepG2 cells. As shown in Fig 1, treatment with increasing concentration of DIM at 40,50 and $60 \mu \mathrm{M}$ for $24 \mathrm{~h}, 48 \mathrm{~h}$ and $72 \mathrm{~h}$ obviously inhibited the proliferation of these cells in a time- and dose-dependent manner. Specifically, after treatment of $\mathrm{DIM}$ at $40 \mu \mathrm{M}$ for $24 \mathrm{~h}$ the survival rate of SMMC-7721 cells was 71\%, MHCC-97H cells 75\%, QGY-7701 cells $78 \%$, Bel-7402 cells $82 \%$, and HepG2 $83 \%$ of control un-treated cells. The inhibition has statistical significance (all $P<0.01$ ). With increasing the dose and time of treatment, the effect of inhibition increased accordingly. These results suggested that DIM could efficiently inhibit the proliferation of hepatocellular carcinoma cells. This result was consistent with previous works of us and others.

\section{FAK and MMP2/9 up-regulated in SMMC-7721 and MHCC-97H cells}

To investigate the ability of migration and invasion of HCC cells, we used transwell assay and found that SMMC-7721 and MNCC-97H cells invaded through the transwell membrane coated with Matrigel more efficient than other cell lines as shown in Fig 2A. Previous studies show that FAK is overexpressed in HCC cell lines, and the level of FAK expression correlated with cell migration and invasion [2]. We explored the expression of FAK and phosphorylated FAK (Tyr397) in these cell lines and found that SMMC-7721 and MNCC-97H cells have higher levels of FAK and phosphorylated FAK (Tyr397) compared with other cell lines with lower potential of invasion (Fig 2B). This result was consistent with previous report [2]. Because MMP2/9 play important roles in tumor invasion and metastasis $[20,21]$, FAK contributes to the invasion and metastasis of HCC partly through regulating expression and activation of both MMP-2 and MMP-9 [2]. We tested the expression of MMP2/9 in these cell lines and found that there were higher expressions of MMP2/9 in SMMC-7721 and MNCC-97H cells compared with that in other cell lines (Fig 2B). Therefore, SMMC-7721 and MHCC-97H cells were chosen to be our target cells in the following steps to study the inhibitory effects of DIM on the metastasis of HCC cells.

\section{DIM inhibited the adhesion, migration and invasion of SMMC-7721 and MHCC-97H cells}

Tumor metastasis is a dynamic hallmark of cancer which consists of three essential events; migration of cancer cells from a primary foci to secondary organs, adhesion of cancer cells at the secondary site and invasion of extracellular matrix (ECM) of secondary organ $[22,23]$. We used wound healing assay to investigate the migration ability of SMMC-7721 and MHCC-97H cells. As shown in Fig 3A, we found that treatment of 30,40 and $50 \mu \mathrm{M}$ DIM for $72 \mathrm{~h}$ reduced the ability of SMMC-7721 cells to migrate from one end of wound to the other. This result was further confirmed by transwell assay. We found that DIM significantly reduced the number of SMMC-7721 and MHCC-97H cells migrating through the transwell membrane to the lower chamber in a concentrationdependent manner, in which DIM at the concentration of $15 \mu \mathrm{M}$ decreased migrating SMMC-7721 cell number to $52 \%$ and $\mathrm{MHCC}-97 \mathrm{H}$ cell numbers to $67 \%$ of the 

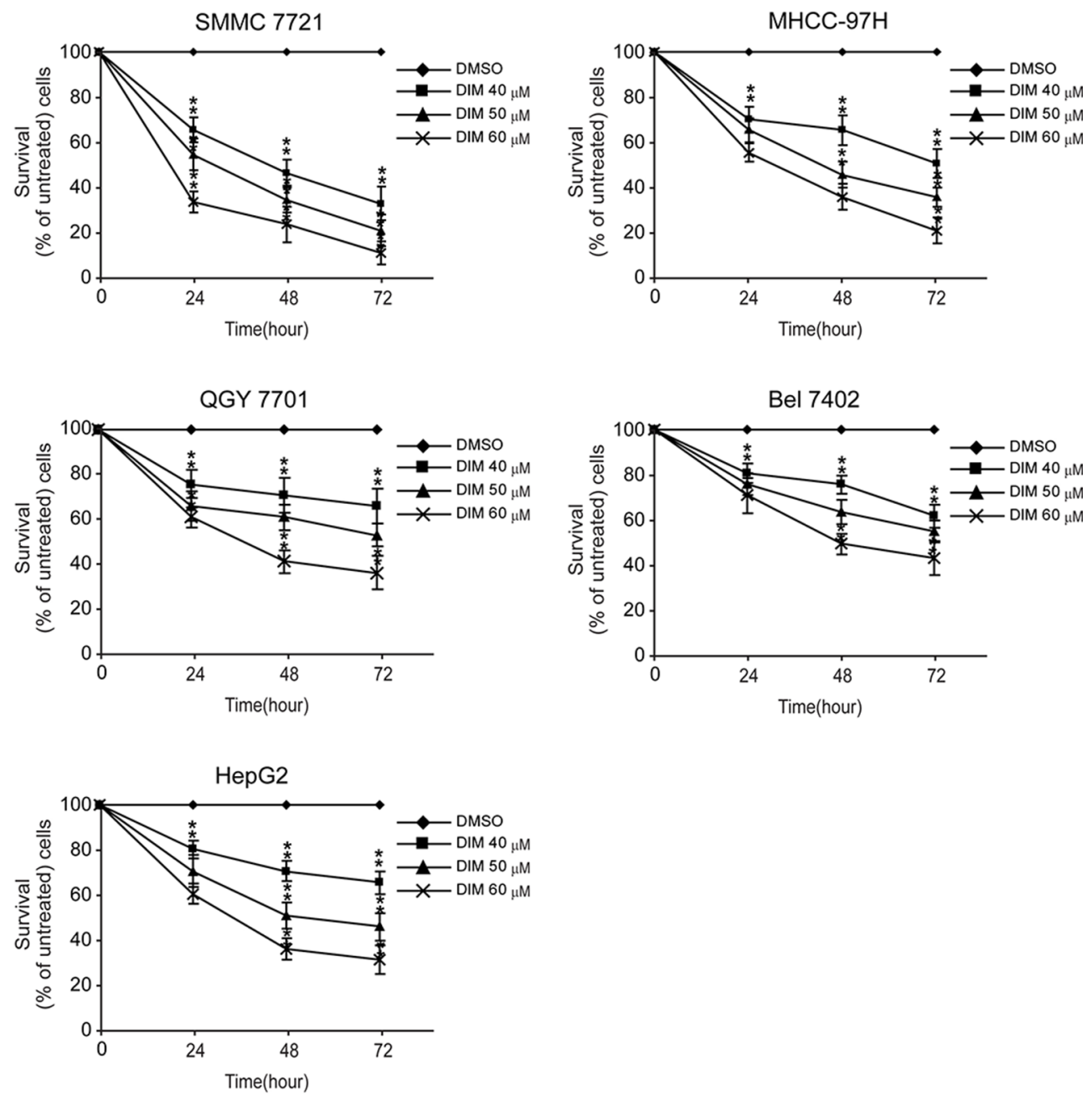

Figure 1: Effects of DIM on the proliferation of HCC cells. SMMC-7721, MHCC-97H, QGY-7701, Bel-7402 and HepG2 cells were treated without or with increasing concentration of DIM (30, 40 and $60 \mu \mathrm{M}$ for 24, 48 and $72 \mathrm{~h})$. After treatment, WST-1 was added and incubated for $2 \mathrm{~h}$ at $37^{\circ} \mathrm{C}$. Light absorbance was recorded at $450 \mathrm{nM}$. Inhibition of DIM on cell proliferation was calculated based on the absorbance ration between treatment and control. Values represent mean $\pm \mathrm{SD}$ of three independent experiments. ${ }^{*} P<0.05, * * P<0.01$, $* * * P<0.001$ compared with the untreated control (dose 0 ).

control (Fig 3B). The effect of decreased migration was of statistical significance and could also be seen at the concentration of $10 \mu \mathrm{M}$ in both cell lines. These results demonstrated that DIM could inhibit the migration of HCC cells.

The inhibitory effect of DIM on cell adhesion was also investigated on these two cell lines. The results were shown as Fig 3C. We found that DIM significantly decreased the number of cells adhered to cell culture dishes in a concentration-dependent manner. At the concentration of $50 \mu \mathrm{M}$, DIM decreased the adhered cell number of SMMC-7721 and MHCC-97H to 35\% and 22\% of control respectively $(P<0.01)$.

The inhibitory effect of DIM on invasion was investigated by examining the ability of SMMC7721 and MHCC-97H cells cross through a simulated extracellular matrix. As shown in Fig 3D, treatment of DIM at concentrations from $10 \mu \mathrm{M}$ to $20 \mu \mathrm{M}$ inhibited the invasion ability of SMMC-7721 and MHCC-97H at a concentration-dependent manner. When cells were treated with DIM at $10 \mu \mathrm{M}$, only $77 \%$ and $50 \%$ of SMMC-7721 and MHCC-97H could invade through the simulated extracellular matrix and migrate to the insert part. In the presence of $20 \mu \mathrm{M}$ DIM, SMMC-7721 and MHCC-97H could hardly transverse and migrate into the lower part of insert. Taken together, these results indicated that DIM acted directly on SMMC-7721 and MHCC-97H to inhibit the processes of proliferation, migration and invasion.

\section{DIM inhibited FAK phosphorylation and decreased the expressions and activities of MMP-2 and MMP-9}

To find out if DIM could inhibit FAK phosphorylation, we treated SMMC-7721 and MHCC$97 \mathrm{H}$ cells with DIM at the concentration of $10 \mu \mathrm{M}, 15 \mu \mathrm{M}$ 

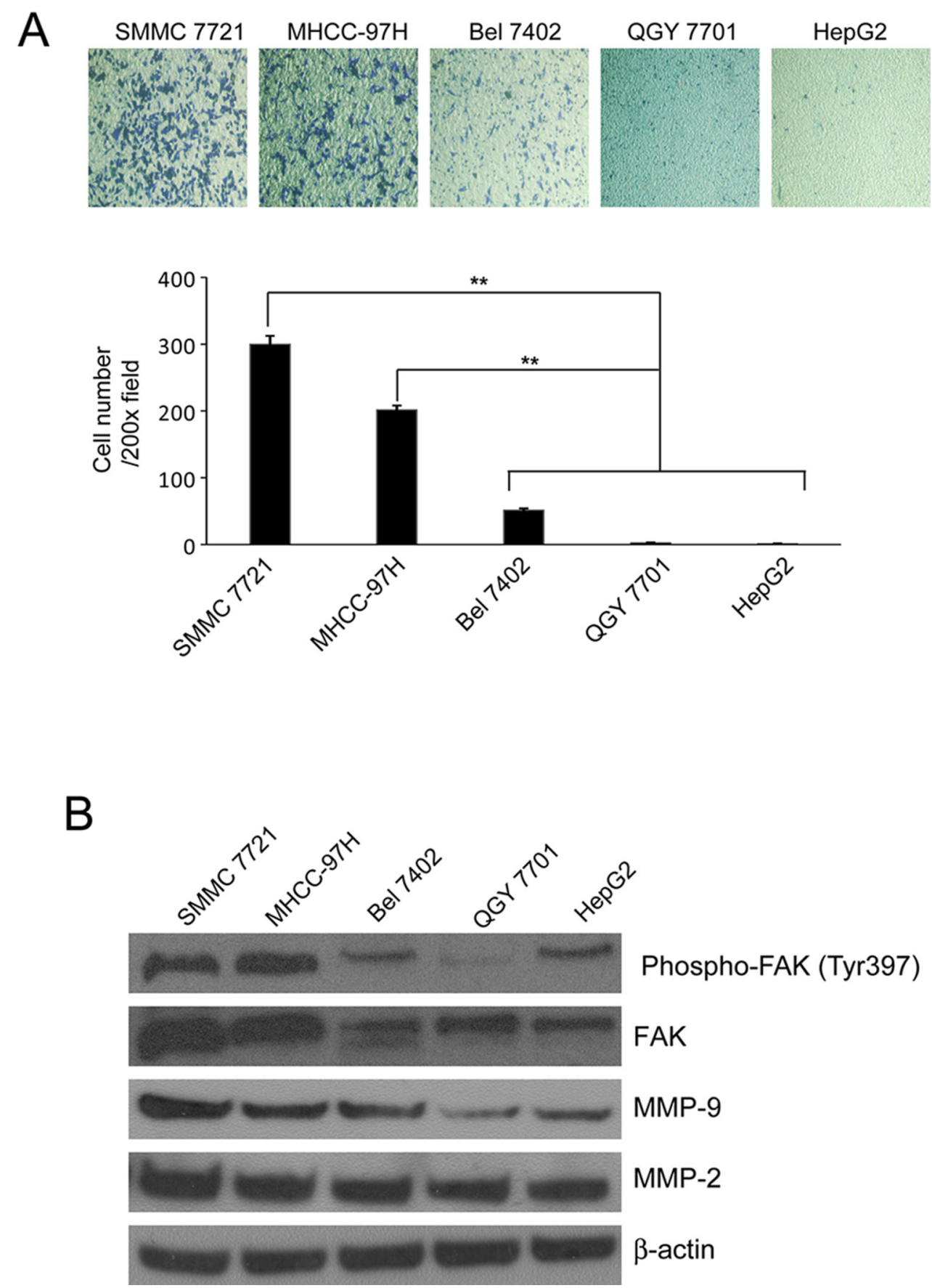

Figure 2: The invasiveness and the expression of FAK, phosphorylated FAK Tyr397 and MMP2/9 in HCC cells. A. Transwell inserts were used. SMMC-7721, MHCC-97H, QGY-7701, Bel-7402 and HepG2 cells were seeded in inserts with $200 \mu \mathrm{l}$ no-serum medium containing $1 \times 10^{5}$ cells, $800 \mu \mathrm{l}$ medium containing $5 \% \mathrm{FBS}$ was added in bottom wells and cells were incubated for 24 hours and stained with Giemsa. B. Cells were cultured in medium containing 5\% FBS and collected. The cell lysates were subjected to Western blotting analysis using antibodies against FAK, phosphorylated FAK Tyr397 and MMP2/9. $\beta$-Actin was used as loading control. Mean \pm SD of three independent experiments were represented. ${ }^{*} P<0.05,{ }^{*} * P<0.01, * * * P<0.001$ compared with the untreated control (dose 0).

and $20 \mu \mathrm{M}$ in serum-free culture media for $48 \mathrm{~h}$ and analyzed the phosphorylation status of FAK. As shown in Fig 4A, we found that DIM decreased the expression of phosphorylated FAK, while the total FAK levels remain constant in both cell lines.
In order to determine if DIM could modulate MMP-2 and MMP-9 expression and activity, we treated SMMC-7721 and MHCC-97H cells with DIM at the concentration of $10 \mu \mathrm{M}, 15 \mu \mathrm{M}$ and $20 \mu \mathrm{M}$ in serum-free medium. Western blotting and zymography were performed and the results 

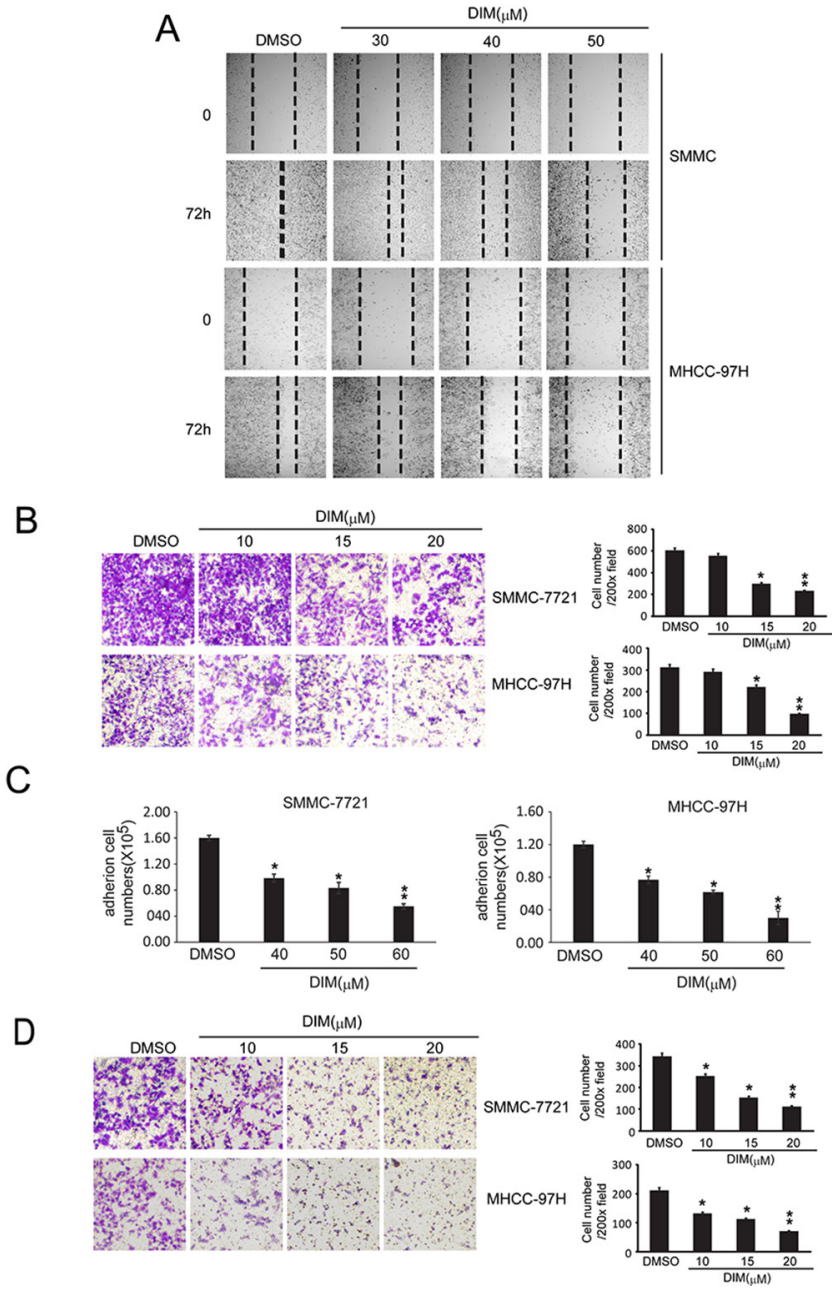

Figure 3: DIM inhibited the adhesion, migration and invasion of SMMC-7721 and MHCC-97H. A. Wound healing assay were conducted. SMMC-7721 and MHCC-97H cells were seeded into 6-well plates and treated with DMSO or DIM $(30 \mathrm{~h}, 40 \mathrm{~h}$ and $50 \mu \mathrm{M}$ for $72 \mathrm{hs})$. Photographs were taken after treatment. B. Migration tests were performed by transwells inserts without basement membrane extract. SMMC-7721 and MHCC-97H $\left(1 \times 10^{5}\right.$ cells per well $)$ were seeded in insert with $200 \mu 1$ no-serum medium containing different concentration of DIM $(5,10$ and $15 \mu \mathrm{M}), 800 \mu \mathrm{l}$ medium containing 5\% FBS was added in bottom wells and cells were incubated for 16 hours. Cells were stained with Giemsa. C. Cell adhesion assay. SMMC-7721 and MHCC-97H were treated in 6-well culture dishes with DIM at 30, 40 and $50 \mu \mathrm{M}$ for 48 hours in medium with $10 \% \mathrm{FBS}$. After that, Cells $\left(5 \times 10^{5}\right.$ cells/well) were plated in 6 -well culture dishes and allowed to adhere for $2.5 \mathrm{~h}$. After that, adhered cells were counted after staining with $0.4 \%$ trypan blue solution. D. Cells invasion assay was performed by transwell inserts with basement membrane extract. SMMC-7721 and MHCC-97H $\left(1 \times 10^{5}\right.$ cells per well $)$ were seeded in inserts with $200 \mu \mathrm{l}$ no-serum medium containing different concentration of DIM (10, 15 and $20 \mu \mathrm{M}), 800 \mu \mathrm{l}$ medium containing $5 \%$ FBS was added in bottom wells and cells were incubated for $24 \mathrm{~h}$. Cells were stained with Giemsa. Values represent mean \pm SD of three independent experiments. ${ }^{*} P<0.05,{ }^{* *} P<0.01,{ }^{* * *} P<0.001$ compared with the untreated control (dose 0 ).

showed that DIM decreased the expression and activity of MMP-2 and MMP-9 compared with control in both cell lines (Fig 4B).

\section{FAK inhibitor decreased the expression of MMP2/9 and suppressed the migration and invasion of HCC cells}

The above results indicated that DIM could inhibit the migration and invasion of HCC cells. At the same time it decreased the expression of phosphorylated FAK and MMP2/9. This implicated that DIM might inhibit cell migration and invasion through the regulation of FAK and MMP2/9. The FAK specific inhibitor PF-562271 inhibits the phosphorylation of FAK tyrosine 397 (Tyr397). We tested the inhibitory effect of PF-562271 and found that PF-562271, at the concentration of 2.0, 4.0 and $6.0 \mu \mathrm{M}$ and treated for 48 hours, decreased the level of phosphorylated FAK without changing the total FAK in both cell lines. (Fig 5A),

In order to find out if PF-562271 could decrease MMP2/9 expression and inhibit cell migration and invasion, we treated the cells with PF-562271 at the concentration of 2.0, 4.0 and $6.0 \mu \mathrm{M}$ for 48 hours, the 
A

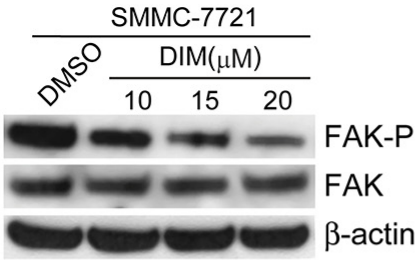

B

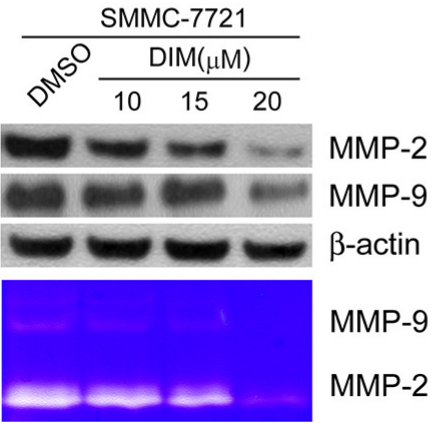

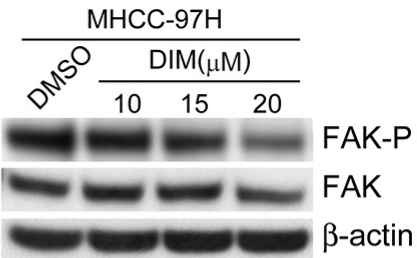

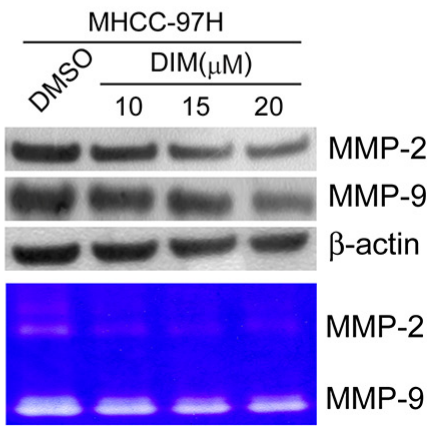

Figure 4: DIM inhibited FAK phosphorylation and decreased the expressions and activities of MMP-2 and MMP-9 in SMMC-7721 and MHCC-97H cells. SMMC-7721 and MHCC-97H cells were treated with DIM at concentration of 10, 15 and $20 \mu \mathrm{M}$ in serum-free medium for 48 hours. A. FAK and the phosphorylated FAK (Y397) was analyzed by Western blotting. $\beta$-Actin was used as loading control. B. Western blot and zymography were used to detect the expression and activity of MMP-2 and MMP-9. $\beta$-Actin was used as loading control.

expression and activity of MMP-2 and MMP-9 were analyzed by Western blotting and zymography. As showed in Fig 5B, PF-562271 decreased the expression and activity of MMP-2 and MMP-9 in a concentrationdependent manner in both cell lines. We also investigated the effect of PF-562271 on migration capability of HCC cells with transwell tests. As shown in Fig 5C, we found that PF-562271 significantly reduced the number of SMMC-7721 and MHCC-97H cells migrating to the lower chamber in a concentration-dependent manner.

The effect of PF-562271 on invasion, was shown in Fig 5D, PF-562271 significantly decreased the number of cells invading the lower surface of inserts compared with the control group in a concentration manner. The inhibition rate of invasion was $30 \%, 45 \%, 60 \%$ of control at 2.0, 4.0, 6.0 $\mu \mathrm{M}$ PF-562271 in SMMC-7721 and 45\%, $55 \%, 85 \%$ of control in MHCC-97H (Fig 5D). These results illustrated that PF-562271, the specific inhibitor of FAK phosphorylation could decrease the invasive and migratory ability of tumor cells through inhibiting FAK pathway mediated MMP-2 and MMP-9 expression and activity.

\section{Silent FAK repressed the expression of MMP2/9 and suppressed the invasion of HCC cells by down-regulation of FAK}

In order to confirm the results concluded from above tests, siRNA for human FAK (si-h-FAK) were used to silent the expression of FAK. siRNA has the advantage of high specificity, high efficiency and easy operation.
As shown in Fig 6A, $48 \mathrm{~h}$ after siRNA transfection, the level of phosphorylated FAK was decreased to $15 \%$ in SMMC-7721 and 21\% in MHCC-97H compared with that in control. In addition, the expression of total FAK was also decreased. In order to find out if si-h-FAK could decrease MMP2/9 expression and inhibit cell invasion, the expression and activity of MMP-2 and MMP-9 were analyzed by Western blotting and zymography $48 \mathrm{~h}$ after transfection. As showed in Fig 6B, si-h-FAK decreased the expression and activity of MMP-2 and MMP-9 in both cell lines. The effect of si-h-FAK on cell invasion was shown in Fig 6C, si-h-FAK significantly decreased the number of cells invading the lower surface of inserts compared with the control group in a concentration dependent manner. The inhibition rate of invasion was $30 \%$ of control in SMMC-7721 and 45\% of control in MHCC-97H (Fig 5C). These results illustrated that si-h-FAK, similar with PF-562271, could decrease the invasive ability of tumor cells through inhibiting FAK mediated MMP-2 and MMP-9 expression and activity.

\section{DIM inhibited cell proliferation, migration and invasion through repressing FAK pathway and associated elements induced by vitronectin}

Vitronectin (VTN) is a multifunctional glycoprotein present in blood and in the extracellular matrix (ECM). It binds to the integrin receptor $\alpha v \beta 3$, activates the integrins/ FAK pathway and involves in the cell attachment, spreading and metastasis [24]. To further test whether DIM could inhibit metastasis and invasion through the 

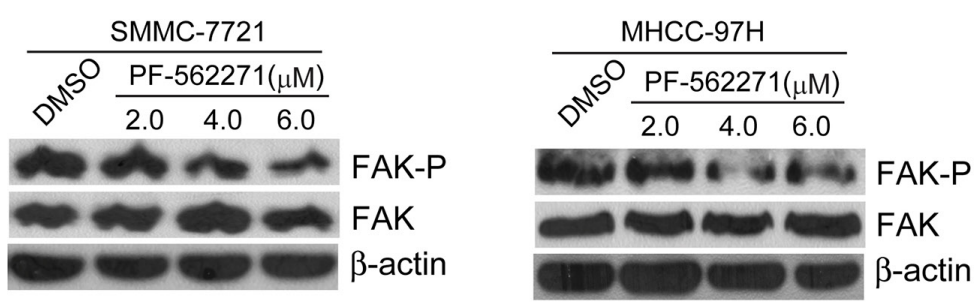

B
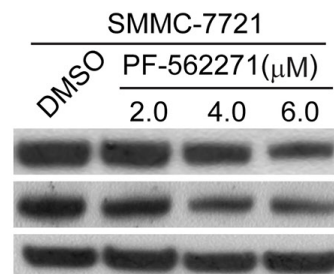

MMP-2

MMP-9

$\beta$-actin

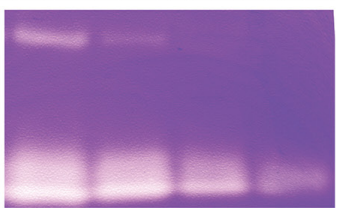

MMP-9

MMP-2

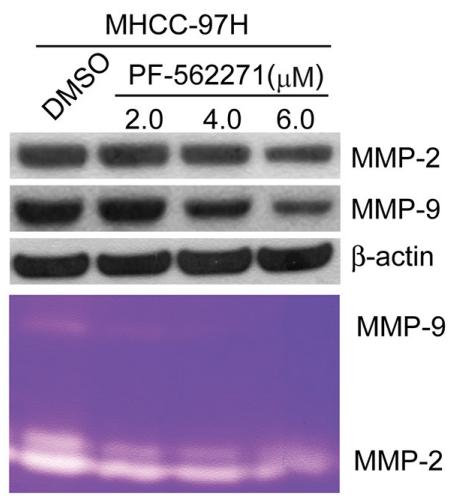

\section{C}

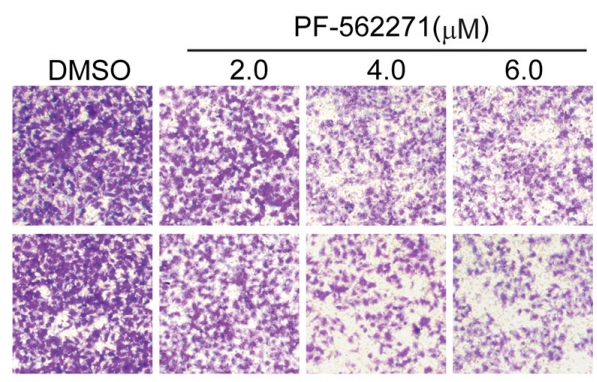

SMMC-7721

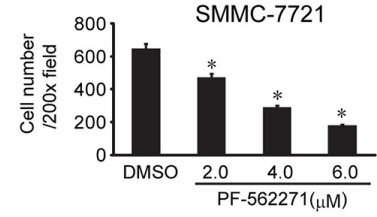

$\mathrm{MHCC}-97 \mathrm{H}$

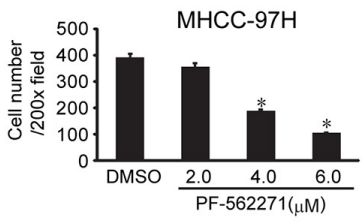

$\mathrm{D}$
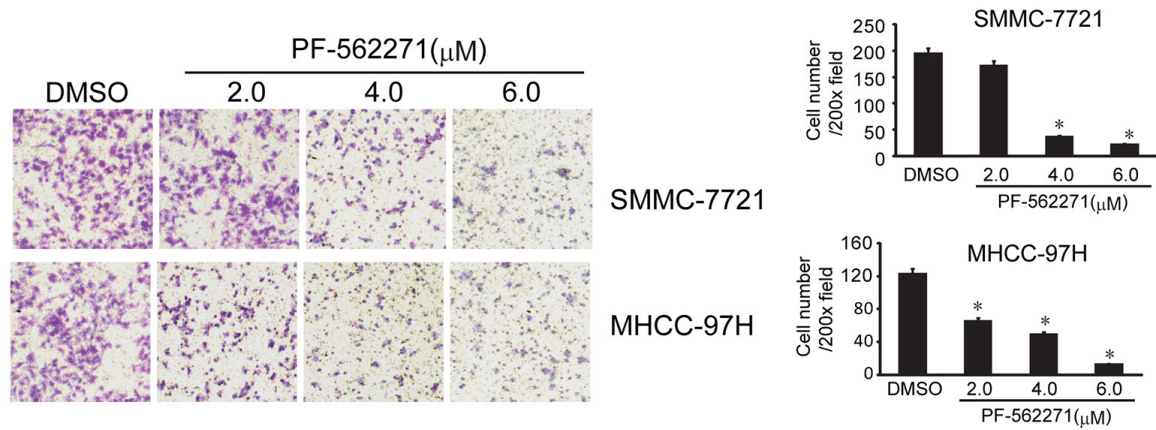

Figure 5: FAK inhibitor PF-562271 decreased the MMP2/9 levels and suppressed the invasion and metastasis of SMMC-7721 and MHCC-97H cells. SMMC-7721 and MHCC-97H cells were treated with PF-562271 at 2, 4 and $6 \mu \mathrm{M}$ in serum-free medium for 48 hours. A. FAK and the phosphorylated FAK (Y397) was analyzed by Western blotting. $\beta$-Actin was used as loading control. B. Western blotting and zymography were used to detect the expression and activity of MMP-2 and MMP-9. $\beta$-Actin was used as loading control. C. Migration tests were performed with transwell, SMMC-7721 and MHCC-97H $\left(1 \times 10^{5}\right.$ cells per well $)$ were seeded in insert in $200 \mu 1$ no-serum medium containing different concentration of PF-562271 (2, 4 and $6 \mu \mathrm{M}), 800 \mu$ medium containing 5\% FBS was added in bottom wells and cells were incubated for 16 hours. Cells were stained with Giemsa. D. Cells invasion was performed via transwell inserts with basement membrane extract. SMMC-7721 and MHCC-97H $\left(1 \times 10^{5}\right.$ cells per well $)$ were seeded in insert in $200 \mu 1$ no-serum medium containing different concentration of PF-562271 (2, 4 and $6 \mu \mathrm{M}), 800 \mu 1$ medium containing 5\% FBS was added in bottom wells and cells were incubated for 24 hours. Cells were stained with Giemsa. Values represent mean \pm SD of three independent experiments. $* P<0.05,{ }^{* *} P<0.01,{ }^{* * *} P<0.001$ compared with the untreated control (dose 0 ). 
A

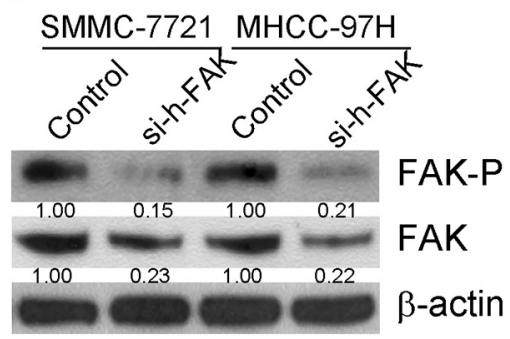

B

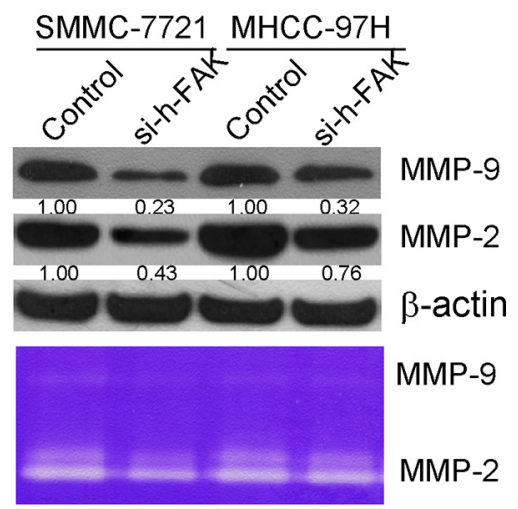

C

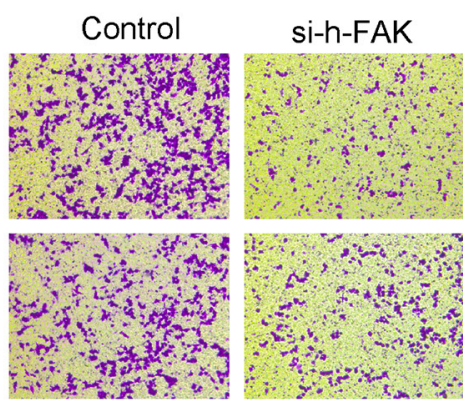

SMMC-7721

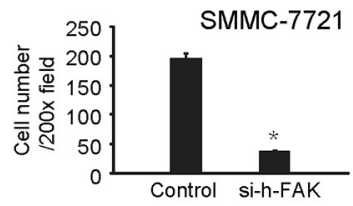

$\mathrm{MHCC}-97 \mathrm{H}$

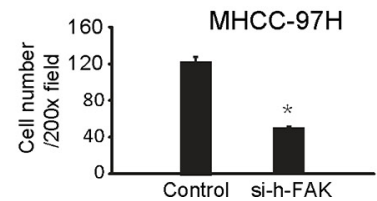

Figure 6: siRNA for FAK(si-h-FAK) down regulated the MMP2/9 levels and suppressed the invasion of SMMC-7721 and MHCC-97H cells by decreasing the levels of phosphorylated FAK and total FAK. SMMC-7721 and MHCC-97H cells were plated in a 6 -well plate $\left(6 \times 10^{5}\right.$ cells/well $)$ and transfected with FAK siRNA or control non-targeted siRNA. Forty-eight hours after transfection, cells were collected for western blotting to confirm the effects of siRNA and other tests. A. FAK and the phosphorylated FAK (Tyr397) were analyzed by Western blotting. $\beta$-Actin was used as loading control. B. Western blotting and zymography were used to detect the expression and activity of MMP-2 and MMP-9. $\beta$-Actin was used as loading control. C. Cells invasion was performed via transwell inserts with basement membrane extract. Cells were stained with Giemsa. Values represent mean \pm SD of three independent experiments. $* P<0.05,{ }^{*} * P<0.01,{ }^{*} * * P<0.001$ compared with the untreated control (dose 0 ).

inactivation of FAK pathway and downstream signal VTN, we used purified human VTN to activate FAK and induce cells invasion.

In the present study, SMMC-7721 and MHCC-97H were treated with DIM $(10,15$ and $20 \mu \mathrm{M})$ in VTN-coated or BSA-coated plate. After $48 \mathrm{~h}$ of treatment, cells were harvested and lysates were analyzed for FAK, phosphoFAK, MMP-2 and MMP-9. Cell conditioned medium were collected for the activity of MMP-2 and MMP-9 in zymography assay. As shown in Fig 7A, cells cultured in VTN coated plates had higher level of phosphorylated FAK compared with that of control, with no obvious change on total FAK. The level of phosphorylated FAK decreased in both cell lines with treatment of DIM. The expression of MMP-2 and MMP-9 and activation of MMP-2 and MMP-9 induced by VTN was also suppressed by the treatment of DIM (Fig 7B).

To examine whether DIM could suppress the invasion of cells induced by VTN, we performed invasion assays using transwell assay. VTN markedly increased invasion of SMMC-7721 (10 verse 230; $P<0.01)$ and MHCC-97H (15 verse 160; $P<0.01$ ), however, DIM significantly decreased the numbers of cell invading through Matrigel-coated filters in a concentrationdependent manner (Fig 7C). These results suggest that DIM could significantly inhibit cell invasion induced by VTN through inactivation of integrin/FAK pathways.

\section{DIM inhibited the activity of FAK by increasing pTEN expression}

PTEN, a lipid phosphatase, is known as an antioncogene which could directly inhibit FAK related pathways through directly dephosphorylation of FAK [25]. To find out whether DIM could change the expression of pTEN, we treated SMMC-7721 and MHCC-97H cells with DIM at 40, 50 and $60 \mu \mathrm{M}$ in 10\% FBS medium and after $48 \mathrm{~h}$ of total treatment, cells were harvested and protein 

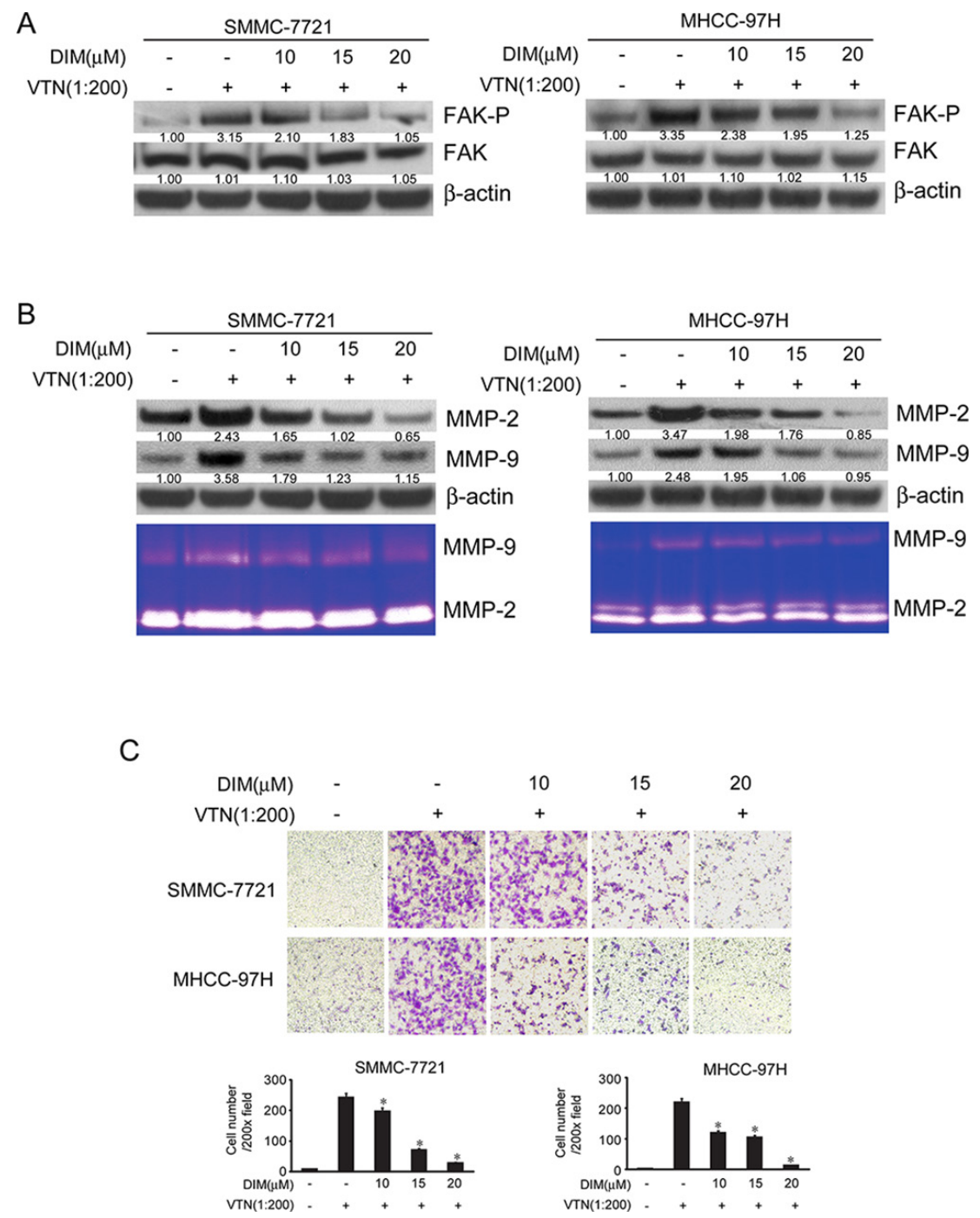

Figure 7: DIM inhibited cell migration and invasion through suppressing the activity of FAK pathway and MMP2/9 expression induced by vitronectin. SMMC-7721 and MHCC-97H cells were treated with DIM $(10,15$ and $20 \mu \mathrm{M})$ on VTN-coated or BSA-coated plate for $48 \mathrm{~h}$. A. Western blotting analysis of cell lysates for FAK and FAP(Y397)-p, MMP-2 and MMP-9. B. Western blotting and zymography assay of MMP-2 and MMP-9. C. Cells invasion was performed via transwell inserts with basement membrane extract. SMMC-772 1 and MHCC-97H $\left(1 \times 10^{5}\right.$ cells per well $)$ were seeded in insert in $200 \mu 1$ no-serum medium containing different concentration of DIM (10, 15 and $20 \mu \mathrm{M})$, the bottom wells were loaded with $800 \mu \mathrm{l}$ no-serum medium containing $5 \mathrm{ng} / \mathrm{ml}$ vitronectin or $5 \mathrm{ng} / \mathrm{ml} \mathrm{BSA}$ and cells were incubated for $24 \mathrm{~h}$. Cells were stained with Giemsa. Values represent mean \pm SD of three independent experiments. $* P<0.05$, $* * P<0.01, * * * P<0.001$ compared with the untreated control (dose 0 ).

extracts were analyzed for pTEN. The immunoblotting results illustrated that DIM obviously increased the expression of pTEN in a concentration-dependent manner compared with control in both cell lines (Fig 8A). To confirm that DIM could inhibit the phosphorylation of FAK through regulating the expression of pTEN, siRNA for human pTEN (si-h-pTEN) was used. As shown in Fig 8B, si-h-pTEN suppressed the over expression of pTEN induced by $60 \mu \mathrm{M}$ DIM in SMMC-7721 and MHCC-97H cells. Additionally, the treatment of si-h-pTEN increased the level of phosphorylation of FAK inhibited by $60 \mu \mathrm{M}$ DIM. These results revealed that pTEN might play a role in downregulation of FAK by DIM.

\section{Oral administration of DIM inhibits lung metastasis of SMMC-7721 cells in BALB/c nude mice}

To determine the effect of DIM on in vivo tumor growth and metastasis, SMMC-7721 cells were injected into the liver to establish an orthotopic liver cancer model. Nude mice were separated randomly into two groups, one group was treated with DIM and the other one was treated with control vehicle. After 6 weeks, nude mice were sacrificed and liver tumor volumes were measured. In the whole experiment, the mean body weights of the DIM treatment group were similar with control groups, 

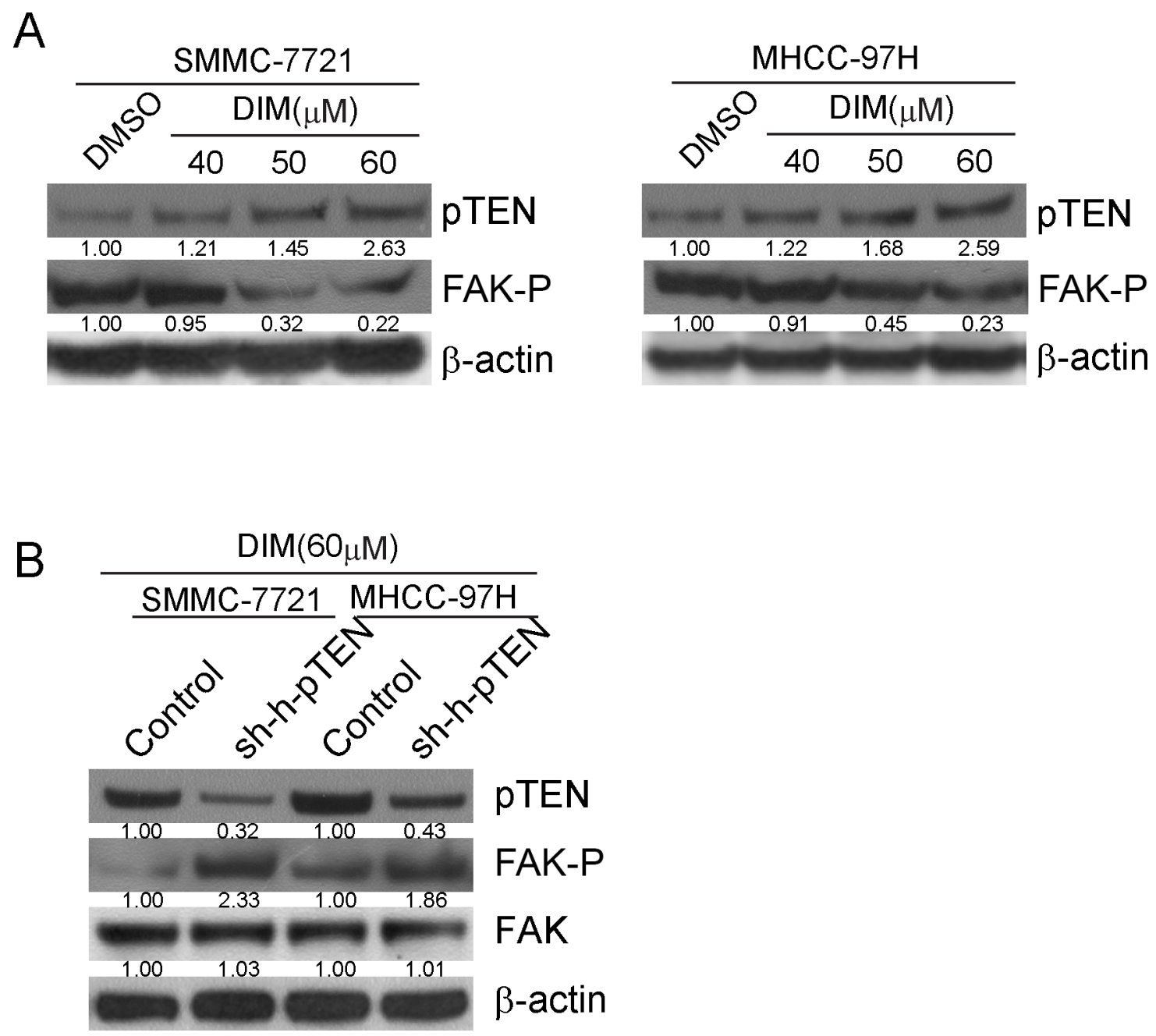

Figure 8: DIM inhibited the phosphorylation of FAK by up-regulating the expression of pTEN. A. SMMC-7721 and MHCC-97H cells were treated with DIM at 40, 50 and $60 \mu \mathrm{M}$ in full medium with $10 \%$ FBS and after $48 \mathrm{~h}$ of treatment, cells were harvested and protein extracts were analyzed for pTEN and FAK-p by Western blotting. B. SMMC-7721 and MHCC-97H cells were firstly transfected with pTEN siRNA or control and then treated with $60 \mu \mathrm{M}$ DIM for $48 \mathrm{~h}$. Cells were harvested and protein extracts were analyzed for pTEN and FAK-p by Western blotting.

except the last week. After 5weeks, the weights of nude mice from control group decreased more quickly than treatment group because of cancer cachexia(Fig 9A). As shown in Fig 9C, the average volume of tumor in nude mice treated by DIM were markedly smaller than the control group $(P<0.01)$. Histological analysis demonstrated that intrahepatic tumor nodules were found larger in control mice than that in mice treated by DIM. To further investigate the effect of DIM on SMMC7721 metastasis in vivo, their lung were collected after sacrificed and the number of nodules on the surface was counted. The mean number of metastatic nodule on the surface of the lung was significantly decreased in mice treated by DIM, compared with control, (2.8 in DIM treated verse 15.2 in control, $P<0.01$ ) (Fig 9B). Pathological analysis demonstrated larger and greater number of tumor nodules in control mice while DIM treated mice displayed metastatic tumors that are fewer and smaller in size (Fig 9B). The expression of FAK, p-FAK, pTEN, MMP-2 and MMP-9 were analyzed by Western blotting. Consistent with our in vitro results, the expression of phosphorylated FAK and MMP2/9 in DIMtreated mice were significantly decreased compared with that in control mice, and the pTEN expression was also increased by DIM (Fig 9D). Taken together, our results from both in vitro and in vivo assays illustrated that DIM can inhibit the formation and metastasis of hepatocellular carcinoma through FAK signaling pathway.

\section{DISCUSSION}

HCC is a common malignancy in many countries [26]. The low survival rate of late stage HCC is largely due to its high rate of intrahepatic and extra-hepatic metastasis [27]. DIM, the predominant active product of phytochemical indole-3-carbinol (I3C) from vegetables 


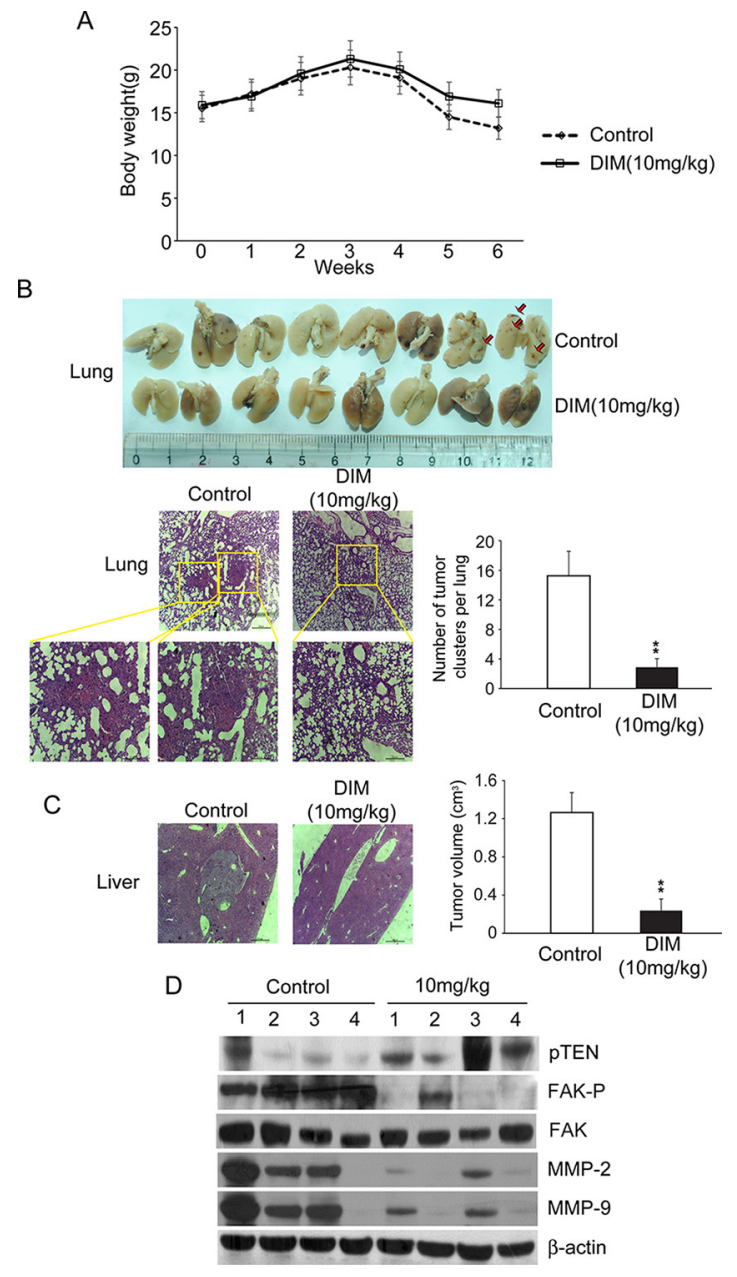

Figure 9: Oral administration of DIM inhibits lung metastasis of SMMC-7721 cells in BALB/c nude mice. $5 \times 10^{5}$ SMMC-7721 cells were injected into the liver of BALB/c nude mice to establish orthotopic liver cancer model. Nude mice were separated randomly into two groups, one group were treated with $10 \mathrm{mg} / \mathrm{kg}$ of DIM and the other were treated with control vehicle. After 6 weeks, nude mice were sacrificed. A. Line graph showing control and treated nude mice body weight (g) over a six weeks period. B. Lung metastasis was observed in the lungs of mice. Only a few metastases were found in mice treated with DIM. The number of lung metastatic nodules on the surface was counted; representative hematoxylin and eosin (HE) staining confirmed the development of tumor in lung tissue. High-power magnification images (400X) of the same field were showed in blow. C. The development of in situ tumors were observer in livers, the volume of tumors were calculated and compared with control. D. Protein samples from in situ tumors of livers were analyzed for FAK, FAP-p, pTEN, MMP-2 and MMP-9 by Western blotting. $\beta$-Actin was used as loading control.

of the family cruciferous [12], inhibits tumor formation in the early phase of tumor genesis, induces cancer cells apoptosis and suppresses cancer cells metastasis or invasion in multiple types of cancer [13-18]. So far, little is known about the tumor inhibitory effect of DIM on HCC. In the current research, we used two HCC cell lines SMMC-7721 and MHCC-97H that have high potential of malignant invasion to investigate the anti-tumor effect of DIM. We found that DIM inhibited the proliferation, migration and invasion of these two cell lines. We further demonstrated the role of DIM in suppressing tumor metastasis through a mouse liver cancer model.

FAK plays a central role in many types of cell events including proliferation, survival, apoptosis, migration and invasion $[28,29]$. FAK has been shown to be very important in the development of liver tumors. Chen et al. found FAK and phospho-FAK Tyr397 were overexpressed in HCC samples and HCC cell lines. The elevated FAK and phospho-FAK Tyr397 were correlated with tumor stage and vascular invasion in hepatocellular carcinoma [2]. In vitro and in vivo tests show that up-regulating FAK promotes tumor metastasis [30-32]. In our study, we detected FAK and phospho-FAK Tyr397 in several HCC cell lines, and also found that FAK and phosphoFAK Tyr397 were overexpressed in SMMC-7721 and MHCC-97H cells that have higher invasive potential compared with other cell lines. Previously, some researchers found that inhibition of FAK phosphorylation by siRNA or FAK specific inhibitors could suppress HCC cell adhesion, migration and invasion [2, 33-35]. We investigated whether DIM inhibited HCC cell metastasis through down-regulation of FAK. When SMMC-7721 
and $\mathrm{MHCC}-97 \mathrm{H}$ were treated with different concentration of DIM, we found a significantly decreased level of phosphorylated FAK Tyr397. In order to confirm the results of FAK inhibition, we used a FAK specific inhibitor PF-56227. PF-56227interacts with FAK in the adenosine triphosphate (ATP) binding pocket and blocks the catalytic activity of FAK [36]. When phospho-FAK Tyr397 were inhibited by PF-56227 in SMMC-7721 and MHCC-97H cells, the metastatic ability of these two cell lines decreased. Similar conclusions were obtained after suing si-h-FAK to confirm the results observed through using PF-56227. We suggested that DIM might inhibit the migration and invasion of hepatocellular carcinoma cells through FAK signaling pathway.

Activation and phosphorylation of FAK by ECMintegrins is an important phenomena for tumor cells to achieve migratory phenotype [29]. Vitronectin (VTN), a multifunctional glycoprotein present in blood and in the ECM, involves in the cell attachment, spreading and metastasis [24]. FAK is localized in focal contacts that becomes tyrosine phosphorylated and subsequently activated on integrin-mediated cell adhesion to several matrix proteins, including VTN [37]. The highly invasive human cancer cells expressing integrin receptor $\alpha v \beta 3$ binds to VTN and generates a migratory phenotype through the activation of FAK signaling [38]. In our study, purified human VTN was used to investigate the relationship of VTN and the anti-metastasis effect of DIM. The results illustrated that VTN increased the expression of phospho-FAK Tyr397 in SMMC-7721 and MHCC-97H cells and promoted invasions of these two cell lines in transwell tests. When DIM was added, the high level of phospho-FAK Tyr397 induced by VTN decreased and invasive potential of two cell lines weaken as well. The results further confirmed that DIM inhibited the migration and invasion of these two cell lines through FAK pathway.

The invasive nature of malignant tumors has been associated with the ability of tumors to degrade extracellular matrix [39]. Matrix metalloproteinase (MMPs), a family of zinc-dependent endopeptidases, could degrade almost all ECM components and involved in the tumor metastatic cascade [20, 39]. MMP2/9 are the main components of MMPs and closely associated with migration and invasion in $\mathrm{HCC}[7,40]$. In our study, we found that MMP2/9 are overexpressed in SMMC-7721 and MHCC-97H cells compared to other cell lines. This might be related to the high potential of invasion [21]. When we treated SMMC-7721 and MHCC-97H cells with DIM, we found that DIM could decrease the expression level and activity of MMP2/9 in these two HCC cell lines. These results were consistent with other reports which confirmed that DIM could inhibit the migration of cancer cells through down-regulating MMPs, including those in thyroid cancer [41], breast cancer [42] and prostate cancer $[17,43]$. Accumulated evidence suggested that FAK play an important role in the regulation of MMP2/9, overactivation of FAK could induce MMP2/9 expression and promote cells invasion [44, 45]. Down-regulation of FAK could inhibit HCC cell migration and invasion partly through down-regulating expressions and activations of both MMP-2 and MMP-9 [2]. In our research, PF-56227, the inhibitor of FAK, decreased the expression and activation of MMP2/9 through the inhibition of FAK phosphorylation in SMMC7721 and MHCC-97H cells. In the test of cell invasion induced by VTN, the expression and activation of MMP2/9 increased and this effect might be induced by the activation of FAK. When DIM was added, the level of phosphorylated FAK Tyr397 and the expression and activation of MMP2/9 were suppressed. We suggested that DIM might suppress the expression and activation of MMP2/9 through inactivation of FAK and lead to the anti-metastasis. The results of our in vivo orthotopic liver cancer model demonstrated that DIM inhibited liver cancer growth and decreased its metastasis to lung. DIM also inhibited the level of phosphorylated FAK Tyr397 and decreased the expression of MMP2/9 in liver tumor tissues.

How did DIM regulate the phosphorylation of FAK? PTEN, known as an anti-oncogene, could directly inhibit FAK related pathways through directly de-phosphorylation of FAK [25]. Recently, Sarkar et al. found that DIM could up-regulate pTEN expression through down-regulating the expression of miR-221 and lead to the inhibition of cell proliferation and migration of pancreatic cancer cells [46]. In our study, we observed that DIM increased the expression of pTEN in both hepatocellular carcinoma cell lines, and si-h-pTEN could inhibit the effects of DIM on FAK phosphorylation. In in vivo tests, the expression of pTEN increased by addition of DIM. We speculated that pTEN might play a role in DIM regulation of FAK.

In summary, our data demonstrated that DIM could inhibit the proliferation, invasion and migration of hepatocellular carcinoma cells both in vivo and in vitro. These inhibitory effects are through increasing pTEN expression and inhibiting FAK phosphorylation leading to decreased MMP2/9 expression and activation. Since long-term exposure to DIM produced no observable toxicity and DIM is a less efficacious inducer of CYPs [47], DIM could be a promising anti-cancer drug in the future.

\section{MATERIALS AND METHODS}

\section{Cell lines and cultures}

HCC cell lines (HepG2, QGY-7701, Bel-7402, SMMC-7721 and MHCC-97H) were obtained from the Cell Bank of the Chinese Academy of Sciences (Shanghai, China) and cultured in Gibco ${ }^{\circledR}$ RPMI Media 1640 with $10 \%$ fetal bovine serum(FBS), penicillin $(100 \mathrm{U} / \mathrm{ml})$ and streptomycin $(100 \mathrm{mg} / \mathrm{ml})$. All cells were grown as monolayer cultures and maintained in a humidified atmosphere of $5 \% \mathrm{CO}_{2}$ in air at $37^{\circ} \mathrm{C}$. Penicillin, streptomycin, RPMI media 1640 and FBS 
were purchased from Life Technologies, Inc. (Grand Island, NY).

\section{Reagents and antibodies}

DIM was purchased from Sigma-Aldrich (St Louis, MO) and dissolved in DMSO to make a $100 \mathrm{mmol} / \mathrm{L}$ stock solution and stored at $-20^{\circ} \mathrm{C}$ in multiple aliquots. PF-562271(N-methyl-N- $\{3-[(\{2-[(2-$ oxo-2, 3-dihydro-1H-indol-5-yl)amino]-5-(trifluoromethyl) pyrimidin-4-yl\}amino) methyl]pyridin-2-yl\}methane sulfonamide), was obtained from Selleckchem (Houston, TX) and dissolved in DMSO to make a $10 \mu \mathrm{mol} / \mathrm{L}$ stock solution and stored at $-20^{\circ} \mathrm{C}$. Vitronectin was obtained from Life Technologies, Inc. (Grand Island, NY) and dissolved in phosphate buffered saline with calcium and magnesium $\left(0.90 \mathrm{mM} \mathrm{CaCl}_{2}, 0.49 \mathrm{mM} \mathrm{MgCl}, 2.67 \mathrm{mM} \mathrm{KCl}, 1.47 \mathrm{mM}\right.$ $\mathrm{KH}_{2} \mathrm{PO}_{4}, 137.93 \mathrm{mM} \mathrm{NaCl}, 8.06 \mathrm{mM} \mathrm{Na} \mathrm{HPO}_{4}$ ) to make a $0.5 \mathrm{ug} / \mathrm{ml}$ stock solution. Antibodies against Phospo-FAK (Tyr397), FAK, MMP-2, MMP-9, pTEN, $\beta$-actin were purchased from Cell Signaling.

\section{Cell proliferation assay}

Cell proliferation was assessed by WST-1 Cell Proliferation and Cytotoxicity Assay Kit (C0035, Beyotime Institute of Biotechnology, China). In brief, HepG2, Bel-7402, QGY-7701, SMMC-7721 and MHCC$97 \mathrm{H}$ were seeded in $96-$ well plates at $2.5 \times 10^{3}$ cells/well and allowed to adhere for $24 \mathrm{~h}$. Then cells were treated with increasing concentration of DIM $(30 \mu \mathrm{M}, 40 \mu \mathrm{M}$ and $60 \mu \mathrm{M}$ ) in 1640 complete medium for $24 \mathrm{~h}, 48 \mathrm{~h}$ and $72 \mathrm{~h}$. After treatment, WST-1 was added to each well and incubated for $2 \mathrm{~h}$ at $37^{\circ} \mathrm{C}$. Absorbance was recorded at $450 \mathrm{nM}$. Inhibition of DIM on cell proliferation was calculated based on the absorbance ration between treatment and control.

\section{Cell adhesion assay}

SMMC-7721 and MHCC-97H cells were treated with DIM at 30, 40 and $50 \mu \mathrm{M}$ for $48 \mathrm{~h}$. After that, Cells $\left(5 \times 10^{5}\right.$ cells/well $)$ treated by DIM were plated in 6-well culture dishes and allowed to adhere for $2.5 \mathrm{~h}$. After that, medium with non-adhered cells was discarded and wells were gently washed twice with PBS to remove any loosely attached cells. Adhered cells were stained with $0.4 \%$ trypan blue solution (SigmaAldrich, St. Louis, MO) and counted. Adhered cells were counted and data expressed as percent decrease in adhered cell count for cells treated with DIM relative to control cells.

\section{Wound healing assay}

Cell migration was analyzed by a wound healing assay [48]. In brief, SMMC-7721 and MHCC-97H cells were seeded into 6-well plates and allowed to confluent. A scratch wound in confluent monolayer was made using a pipette tip. After washing away all detached cells with PBS, the remaining cells were treated with DMSO or DIM in fresh complete medium. Photographs were taken at $48 \mathrm{~h}$ and $72 \mathrm{~h}$ after treatment.

\section{In vitro cell migration and invasion assay}

In order to test the ability of cells migration, $6.5 \mathrm{~mm}$ Transwell ${ }^{\circledR}$ with $8.0 \mu \mathrm{m}$ Pore Polyester Membrane Insert (Product \#3464, Corning, Inc., Corning, NY) was used. In order to test the invasion ability of cells crossing through matrigel-coated filter, $6.5 \mathrm{~mm}$ Transwell ${ }^{\circledR}$ with $8.0 \mu \mathrm{m}$ Pore Polycarbonate Membrane Insert coated with Cultrex ${ }^{\circledR}$ Basement Membrane Extract (BME) (Product\#3432-001-01, Trevigen Inc.) were used. The procedure was performed as described previously [49]. Cells were starved for $18 \mathrm{~h}$ using no-serum medium and then $1 \times 10^{5}$ cells per well were seeded in insert with $200 \mu 1$ no-serum medium with or without DIM, and $800 \mu 1$ of growth medium containing 5\% FBS was added in bottom wells. Following a culture of $16 \mathrm{~h}$, nonmigrating cells were removed from the upper surface by wiping with a cotton swab. The membrane was fixed with $4 \%$ formaldehyde for $15 \mathrm{~min}$ at room temperature. Cells were stained with Giemsa for $25 \mathrm{~min}$, and their numbers in 5 fields of each membrane were counted under an inverted microscope. The procedure of PF-562271 was the same as that of DIM, the no-serum medium containing different concentration of PF-562271 was loaded in inserts. For the co-treatment of vitronectin and DIM, the same procedures were used except that the bottom wells were loaded with no-serum medium containing $5 \mathrm{ng} / \mathrm{ml}$ vitronectin or $5 \mathrm{ng} / \mathrm{ml}$ BSA.

\section{Western blotting analysis}

Whole cell lysate preparation and Western blotting analysis were performed as previously described [50]. Briefly, cells were pelleted by centrifugation at $320 \times \mathrm{g}$ for $10 \mathrm{~min}$ and suspended in lysis buffer $(20 \mathrm{mM}$ Tris- $\mathrm{HCl}$ $\mathrm{pH}$ 7.4, $2 \mathrm{mM}$ EDTA, $500 \mathrm{mM}$ sodium orthovanadate, $1 \%$ Triton X-100, 0.1\% SDS, $10 \mathrm{mM} \mathrm{NaF}, 10 \mathrm{mg} / \mathrm{mL}$ leupeptin, and $1 \mathrm{mM}$ PMSF). Aliquots $(20 \mathrm{mg}$ ) of the lysates were separated on a 4-12\% SDS-polyacrylamide gel and transferred into a PVDF membrane (Millipore, USA). Blots were blocked for $2 \mathrm{~h}$ in blocking buffer (5\% non-fat dry milk in PBST buffer $(10 \mathrm{mM}$ phosphate buffer, $2.7 \mathrm{mM} \mathrm{KCl}, 140 \mathrm{mM} \mathrm{NaCl}$ and $0.05 \%$ Tween 20, $\mathrm{pH} 7.4)$ ) and incubated with primary antibodies $(1: 1000)$ overnight at $4^{\circ} \mathrm{C}$. After washing with PBST, the appropriate HRP-conjugated secondary antibody (1:5000) was added to the preparation. The blot was incubated at $37^{\circ} \mathrm{C}$ for $1 \mathrm{~h}$ and developed using an enhanced chemiluminescence detection system (Beyotime Institute of Biotechnology, China). 


\section{MMP detection}

The activity of MMP-2 and MMP-9 was detected through gel zymography as described before [51]. Briefly, SMMC-7721 and MHCC-97H cells were seeded at a density of $5 \times 10^{4}$ cells per well in 6 -well culture dishes and allowed to adhere overnight. Then they were switched to serum free medium and incubated with different concentration of DIM, PF-562271 or left untreated for $48 \mathrm{~h}$. Conditioned medium were harvested and centrifuged to remove any debris. According to the cell numbers in each well, the total protein concentration of the medium was adjusted to be equal. 10\% SDS-PAGE containing $0.1 \%$ gelatin was used and the conditioned medium was resolved in non-reducing conditions. After electrophoresis, gels were incubated in re-naturation buffer $(2.5 \%$ Triton X-100) for $1 \mathrm{~h}$ on an orbital shaker and switched to developing buffer $(50 \mathrm{mMTris}-\mathrm{HCl} \mathrm{pH}$ $8,5 \mathrm{mM} \mathrm{CaCl}_{2}, 0.02 \% \mathrm{NaN}_{3}$ ) for $1 \mathrm{~h}$ followed by $24 \mathrm{~h}$ at $37^{\circ} \mathrm{C}$ with new developing buffer. Gels were then stained with Comassie blue (G-250) and destained with $30 \%$ methanol and $10 \%$ acetic acid.

\section{VTN coating and treatment}

Because serum contains several kinds of ECM proteins, including VTN, therefore, experiments about VTN were performed under serum-free conditions. Serum-free medium was supplemented with ITS (insulin, transferrin, selenium; Life Technologies, Inc., Rockville, MD). For treatment with the combination of VTN and DIM, the 6 -well cell culture plates were coated with $5 \mu \mathrm{g} / \mathrm{ml} \mathrm{VTN}$ (PHE0011, Life Technologies, Inc. (Grand Island, NY)) and control dishes were blocked with $0.1 \%$ BSA overnight at $4^{\circ} \mathrm{C}$ in PBS and then washed with PBS. SMMC-7721 and MHCC-97H cells at $2.5 \times 10^{3}$ cells/well were allowed to adhere for $24 \mathrm{~h}$. Then cells were treated with increasing concentration of DIM $(30 \mu \mathrm{M}, 40 \mu \mathrm{M}$ and $50 \mu \mathrm{M})$ in 1640 serum-free medium for $48 \mathrm{~h}$. After treatment, cells were collected for Western blot analysis, the conditioned medium were collected for gel zymography.

\section{Transfection of cells with siRNA for FAK or pTEN}

SMMC-7721 and MHCC-97H cells were plated in a 6-well plate $\left(6 \times 10^{5}\right.$ cells/well $)$ and transfected with FAK or pTEN siRNA or control non-targeted siRNA (Guangzhou RiboBio Co., Ltd., China) using lipofectamine TM 2000 (11668-019, Life Technologies, Inc. Grand Island, NY)) according to the manufacturer's instructions. Forty-eight hours after transfection, cells were collected for Western blotting to confirm the effects of siRNA and other tests.

\section{In vivo lung metastasis experiments}

HCC mouse model was created using SMMC-7721 cells. Briefly, SMMC-7721 cells at logarithmic growth phase were collected, washed three times with PBS and adjusted the cell number to $1 \times 10^{8}$ cells $/ \mathrm{ml}$. BALB $/ \mathrm{c}$ nude mice were anesthetized with isofluorane, put in the supine position, and limbs were fixed with rubber band in the thermostatic experimental board. After disinfection with $2 \%$ tincture of iodine and $75 \%$ alcohol, the skin and peritoneum were opened, left lobe of the liver was extruded out of abdominal cavity. Using a micro-syringe, $5 \mu$ l of cell suspension was injected into the left lobe of the liver. After injection, the pinhole was pressed immediately with sterile swab to stop bleeding. Then, the left lobe of liver was put back into the abdominal cavity and the abdominal wall was closed. A week later, nude mice with injection of HCC cells were separated randomly into two groups, one group received $1 \mathrm{mg} / \mathrm{ml}$ DIM (10 mg/kg.d) which was suspended in drinking water with an emulsifier, $0.5 \%$ of ethoxylated castor oil (Sigma, St. Louis, MO). The other group received water with $0.5 \%$ of ethoxylated castor oil as a vehicle control. Mice received a freshly made solution of DIM in their drinking water every 2 days. After 6 weeks, mice were sacrificed, tumors were removed and weighted. One part of tumors were frozen in liquid nitrogen for future analysis, the left, livers and lungs were collected and fixed in formalin, embedded into paraffin. Consecutive sections were made for every block of lung and liver tissue and stained with hematoxylin and eosin. The number of lung metastases was counted and evaluated independently by two pathologists.

\section{Statistical analysis}

The data were presented as the means plus/minors standard deviation. SPSS 11.0 software was used for statistical analysis. The data for time and dosage effects were analyzed using two-way ANOVA. When appropriate, data were analyzed using one-way analysis of variance (ANOVA). The priori significance level was set at $P<0.05$.

\section{CONFLICTS OF INTEREST}

No potential conflicts of interest were disclosed.

\section{FINANCIAL DISCLOSURE}

This work was supported by grants from: 1 . The Guangdong Provincial Department of Science and Technology (2012B060300005); 2. The National Natural Science Foundation of Guangdong Provincial (S2012010009633); 3. The National Natural Science Foundation of China (81101562 and 81402717); 4. Key Project of Guangzhou Medical and Health Science 
and Technology (20121A021018); 5. The Project for Key Medicine Discipline Construction of Guangzhou Municipality (2013-2015-07).

The funders of the study had no role in study design, data collection and analysis, decision to publish, or preparation of the manuscript.

\section{REFERENCES}

1. Jemal A, Bray F, Center MM, Ferlay J, Ward E, Forman D. Global cancer statistics. CA: a cancer journal for clinicians. 2011; 61:69-90.

2. Chen JS, Huang XH, Wang Q, Chen XL, Fu XH, Tan HX, Zhang LJ, Li W, Bi J. FAK is involved in invasion and metastasis of hepatocellular carcinoma. Clinical \& experimental metastasis. 2010; 27:71-82.

3. Casar B, Rimann I, Kato H, Shattil SJ, Quigley JP, Deryugina EI. In vivo cleaved CDCP1 promotes early tumor dissemination via complexing with activated beta1 integrin and induction of FAK/PI3K/Akt motility signaling. Oncogene. 2014; 33:255-268.

4. Shieh JM, Cheng TH, Shi MD, Wu PF, Chen Y, Ko SC, Shih YW. alpha-Tomatine suppresses invasion and migration of human non-small cell lung cancer NCI-H460 cells through inactivating FAK/PI3K/Akt signaling pathway and reducing binding activity of NF-kappaB. Cell biochemistry and biophysics. 2011; 60:297-310.

5. Fong YC, Liu SC, Huang CY, Li TM, Hsu SF, Kao ST, Tsai FJ, Chen WC, Chen CY, Tang CH. Osteopontin increases lung cancer cells migration via activation of the alphavbeta3 integrin/FAK/Akt and NF-kappaB-dependent pathway. Lung cancer. 2009; 64:263-270.

6. Chen YY, Lu HF, Hsu SC, Kuo CL, Chang SJ, Lin JJ, Wu PP, Liu JY, Lee CH, Chung JG, Chang JB. Bufalin inhibits migration and invasion in human hepatocellular carcinoma SK-Hep1 cells through the inhibitions of NF-kB and matrix metalloproteinase-2/-9-signaling pathways. Environ Toxicol. 2015;30:74-82.

7. Chen JS, Huang XH, Wang Q, Huang JQ, Zhang LJ, Chen XL, Lei J, Cheng ZX. Sonic hedgehog signaling pathway induces cell migration and invasion through focal adhesion kinase/AKT signaling-mediated activation of matrix metalloproteinase (MMP)-2 and MMP-9 in liver cancer. Carcinogenesis. 2013; 34:10-19.

8. Han EK, McGonigal T, Wang J, Giranda VL, Luo Y. Functional analysis of focal adhesion kinase (FAK) reduction by small inhibitory RNAs. Anticancer research. 2004; 24:3899-3905.

9. Golubovskaya VM, Figel S, Ho BT, Johnson CP, Yemma M, Huang G, Zheng M, Nyberg C, Magis A, Ostrov DA, Gelman IH, Cance WG. A small molecule focal adhesion kinase (FAK) inhibitor, targeting Y397 site: 1-(2-hydroxyethyl)-3, 5, 7-triaza-1-azoniatricyclo [3.3.1.1 $(3,7)$ ]decane; bromide effectively inhibits FAK autophosphorylation activity and decreases cancer cell viability, clonogenicity and tumor growth in vivo. Carcinogenesis. 2012; 335:1004-1013.

10. Hochwald SN, Nyberg C, Zheng M, Zheng D, Wood C, Massoll NA, Magis A, Ostrov D, Cance WG, Golubovskaya VM. A novel small molecule inhibitor of FAK decreases growth of human pancreatic cancer. Cell cycle. 2009; 8:2435-2443.

11. Alisi A, Balsano C. Enhancing the efficacy of hepatocellular carcinoma chemotherapeutics with natural anticancer agents. Nutrition reviews. 2007; 65:550-553.

12. Ashok BT, Chen YG, Liu X, Garikapaty VP, Seplowitz R, Tschorn J, Roy K, Mittelman A, Tiwari RK. Multiple molecular targets of indole-3-carbinol, a chemopreventive anti-estrogen in breast cancer. European journal of cancer prevention: the official journal of the European Cancer Prevention Organisation. 2002; 11:S86-93.

13. Qian X, Song JM, Melkamu T, Upadhyaya P, Kassie F. Chemoprevention of lung tumorigenesis by intranasally administered diindolylmethane in $\mathrm{A} / \mathrm{J}$ mice. Carcinogenesis. 2013; 34:841-849.

14. McDougal A, Sethi Gupta M, Ramamoorthy K, Sun G, Safe SH. Inhibition of carcinogen-induced rat mammary tumor growth and other estrogen-dependent responses by symmetrical dihalo-substituted analogs of diindolylmethane. Cancer letters. 2000; 151:169-179.

15. Chang X, Tou JC, Hong C, Kim HA, Riby JE, Firestone GL, Bjeldanes LF. 3,3'-Diindolylmethane inhibits angiogenesis and the growth of transplantable human breast carcinoma in athymic mice. Carcinogenesis. 2005; 26:771-778.

16. Rahimi M, Huang KL, Tang CK. 3,3'-Diindolylmethane (DIM) inhibits the growth and invasion of drug-resistant human cancer cells expressing EGFR mutants. Cancer letters. 2010; 295:59-68.

17. Ahmad A, Kong D, Sarkar SH, Wang Z, Banerjee S, Sarkar FH. Inactivation of UPA and its receptor UPAR by 3,3'-diindolylmethane (DIM) leads to the inhibition of prostate cancer cell growth and migration. Journal of cellular biochemistry. 2009; 107:516-527.

18. Li Y, Chinni SR, Sarkar FH. Selective growth regulatory and pro-apoptotic effects of DIM is mediated by AKT and NF-kappaB pathways in prostate cancer cells. Frontiers in bioscience: a journal and virtual library. 2005; 10:236-243.

19. Sun Y, Cheng MK, Griffiths TR, Mellon JK, Kai B, Kriajevska M, Manson MM. Inhibition of STAT signalling in bladder cancer by diindolylmethane: relevance to cell adhesion, migration and proliferation. Current cancer drug targets. 2013; 13:57-68.

20. Fingleton B. Matrix metalloproteinases: roles in cancer and metastasis. Frontiers in bioscience: a journal and virtual library. 2006; 11:479-491.

21. Deryugina EI, Quigley JP. Matrix metalloproteinases and tumor metastasis. Cancer metastasis reviews. 2006; 25:9-34.

22. Gupta GP, Massague J. Cancer metastasis: building a framework. Cell. 2006; 127:679-695. 
23. Hanahan D, Weinberg RA. The hallmarks of cancer. Cell. 2000; 100:57-70.

24. Schvartz I, Seger D, Shaltiel S. Vitronectin. The international journal of biochemistry \& cell biology. 1999; 31:539-544

25. Yamada KM, Araki M. Tumor suppressor PTEN: modulator of cell signaling, growth, migration and apoptosis Journal of cell science. 2001; 114:2375-2382.

26. Braillon A. Hepatocellular carcinoma. Lancet. 2012; 380:469; author reply 470-461.

27. Budhu A, Forgues M, Ye QH, Jia HL, He P, Zanetti KA, Kammula US, Chen Y, Qin LX, Tang ZY, Wang XW. Prediction of venous metastases, recurrence, and prognosis in hepatocellular carcinoma based on a unique immune response signature of the liver microenvironment. Cancer cell. 2006; 10:99-111.

28. Siesser PM, Hanks SK. The signaling and biological implications of FAK overexpression in cancer. Clinical cancer research: an official journal of the American Association for Cancer Research. 2006; 12:3233-3237.

29. McLean GW, Carragher NO, Avizienyte E, Evans J, Brunton VG, Frame MC. The role of focal-adhesion kinase in cancer - a new therapeutic opportunity. Nature reviews Cancer. 2005; 5:505-515.

30. Cheng N, Li Y, Han ZG. Argonaute2 promotes tumor metastasis by way of up-regulating focal adhesion kinase expression in hepatocellular carcinoma. Hepatology. 2013; 57:1906-1918.

31. Su R, Li Z, Li H, Song H, Bao C, Wei J, Cheng L. Grp78 promotes the invasion of hepatocellular carcinoma. BMC cancer. 2010; 10:20.

32. Tang J, Wu YM, Zhao P, Yang XM, Jiang JL, Chen ZN. Overexpression of HAb18G/CD147 promotes invasion and metastasis via alpha3beta1 integrin mediated FAK-paxillin and FAK-PI3K-Ca2+ pathways. Cellular and molecular life sciences: CMLS. 2008; 65:2933-2942.

33. Xiao W, Jiang M, Li H, Li C, Su R, Huang K. Knockdown of FAK inhibits the invasion and metastasis of Tca8113 cells in vitro. Molecular medicine reports. 2013; 8:703-707.

34. Lee S, Qiao J, Paul P, O'Connor KL, Evers MB, Chung DH. FAK is a critical regulator of neuroblastoma liver metastasis. Oncotarget. 2012; 3:1576-1587.

35. Walsh C, Tanjoni I, Uryu S, Tomar A, Nam JO, Luo H, Phillips A, Patel N, Kwok C, McMahon G, Stupack DG, Schlaepfer DD. Oral delivery of PND-1186 FAK inhibitor decreases tumor growth and spontaneous breast to lung metastasis in pre-clinical models. Cancer biology \& therapy. 2010; 9:778-790.

36. Roberts WG, Ung E, Whalen P, Cooper B, Hulford C, Autry C, Richter D, Emerson E, Lin J, Kath J, Coleman K, Yao L, Martinez-Alsina L, Lorenzen M, Berliner M, Luzzio M, et al. Antitumor activity and pharmacology of a selective focal adhesion kinase inhibitor, PF-562, 271. Cancer research. 2008; 68:1935-1944.
37. Vuori K. Integrin signaling: tyrosine phosphorylation events in focal adhesions. The Journal of membrane biology. 1998; 165:191-199.

38. Zheng DQ, Woodard AS, Fornaro M, Tallini G, Languino LR Prostatic carcinoma cell migration via alpha(v)beta3 integrin is modulated by a focal adhesion kinase pathway. Cancer research. 1999; 59:1655-1664.

39. Shuman Moss LA, Jensen-Taubman S, StetlerStevenson WG. Matrix metalloproteinases: changing roles in tumor progression and metastasis. The American journal of pathology. 2012; 181:1895-1899.

40. Ochoa-Callejero L, Toshkov I, Menne S, Martinez A. Expression of matrix metalloproteinases and their inhibitors in the woodchuck model of hepatocellular carcinoma. Journal of medical virology. 2013; 85:1127-1138.

41. Rajoria S, Suriano R, George A, Shanmugam A, Schantz SP, Geliebter J, Tiwari RK. Estrogen induced metastatic modulators MMP-2 and MMP-9 are targets of 3,3'-diindolylmethane in thyroid cancer. PloS one. 2011; 6:e15879.

42. Ahmad A, Kong D, Wang Z, Sarkar SH, Banerjee S, Sarkar FH. Down-regulation of uPA and uPAR by 3,3'-diindolylmethane contributes to the inhibition of cell growth and migration of breast cancer cells. Journal of cellular biochemistry. 2009; 108:916-925.

43. Kong D, Li Y, Wang Z, Banerjee S, Sarkar FH. Inhibition of angiogenesis and invasion by 3,3'-diindolylmethane is mediated by the nuclear factor-kappaB downstream target genes MMP-9 and uPA that regulated bioavailability of vascular endothelial growth factor in prostate cancer. Cancer research. 2007; 67:3310-3319.

44. Lu CC, Yang JS, Chiang JH, Hour MJ, Amagaya S, Lu KW, Lin JP, Tang NY, Lee TH, Chung JG. Inhibition of invasion and migration by newly synthesized quinazolinone MJ-29 in human oral cancer CAL 27 cells through suppression of MMP-2/9 expression and combined down-regulation of MAPK and AKT signaling. Anticancer research. 2012; 32:2895-2903.

45. Kolli-Bouhafs K, Boukhari A, Abusnina A, Velot E, Gies JP, Lugnier $\mathrm{C}$, Ronde $\mathrm{P}$. Thymoquinone reduces migration and invasion of human glioblastoma cells associated with FAK, MMP-2 and MMP-9 down-regulation. Investigational new drugs. 2012; 30:2121-2131.

46. Sarkar S, Dubaybo H, Ali S, Goncalves P, Kollepara SL, Sethi S, Philip PA, Li Y. Down-regulation of miR-221 inhibits proliferation of pancreatic cancer cells through up-regulation of PTEN, p27(kip1), p57(kip2), and PUMA. American journal of cancer research. 2013; $3: 465-477$.

47. Leibelt DA, Hedstrom OR, Fischer KA, Pereira CB, Williams DE. Evaluation of chronic dietary exposure to indole-3-carbinol and absorption-enhanced 3,3'-diindolylmethane in sprague-dawley rats. Toxicological sciences: an official journal of the Society of Toxicology. $2003 ; 74: 10-21$. 
48. Chen P, Gupta K, Wells A. Cell movement elicited by epidermal growth factor receptor requires kinase and autophosphorylation but is separable from mitogenesis. The Journal of cell biology. 1994; 124:547-555.

49. Albini A, Iwamoto Y, Kleinman HK, Martin GR, Aaronson SA, Kozlowski JM, McEwan RN. A rapid in vitro assay for quantitating the invasive potential of tumor cells. Cancer research. 1987; 47:3239-3245.
50. Li WX, Chen SF, Chen LP, Yang GY, Li JT, Liu HZ, Zhu W. Thimerosal-induced apoptosis in mouse $\mathrm{C} 2 \mathrm{C} 12$ myoblast cells occurs through suppression of the PI3K/Akt/ survivin pathway. PloS one. 2012; 7:e49064.

51. Ito A, Nakajima S, Sasaguri Y, Nagase H, Mori Y. Co-culture of human breast adenocarcinoma MCF-7 cells and human dermal fibroblasts enhances the production of matrix metalloproteinases 1, 2 and 3 in fibroblasts. British journal of cancer. 1995; 71:1039-1045. 